Reprod. Nutr. Dévelop., 1981, 21 (4), 585-589.

\title{
Influence du stockage des œufs à couver sur la durée d'incubation ef le taux sérique d'hormones thyroïdiennes chez l'embryon de poulet
}

par S. MUAMBI, E. DECUYPERE *, H. MICHELS *

Département de Biologie, Faculté des Sciences,

Campus de Kinshasa, B.P. 190, Kinshasa XI, Zaïre.

* Laboratorium voor Eco-fysiologie der Huisdieren, Faculteit der Landbouwwefenschappen,

Katholiek Universiteit te Leuven, Kardinaal Mercierlaan, 92, B-3030 Heverlee, Belgique.

Summary. Effect of the length of egg storage on duration of incubation : relation to serum thyroid levels in the chick embryo.

After storage at $12^{\circ} \mathrm{C}$ and 90 to 95 p. 100 humidity, for periods of $1,5,8,11$ and 14 days, Rhode Island Red eggs were incubated at $37.5^{\circ} \mathrm{C}$ and 60 p. 100 humidity.

Whatever the total duration of incubation within the experimental conditions, maximal serum levels of triiodothyronine $\left(T_{3}\right)$ and thyroxine $\left(T_{4}\right)$ were obtained the day of pipping. Embryos having perforated the air-space membrane the day before pipping showed elevated serum $T_{3}$, but not $T_{4}$, levels as compared to embryos without a perforation.

The lower serum $\mathrm{T}_{3}$ levels, obtained at pipping, after longer periods of preincubation storage are discussed in relation to other experiments on perinatal changes in serum iodohormones.

\section{Introduction.}

On connaît les effets du stockage des œufs à couver sur la durée d'incubation ; mais le mécanisme biochimique de cette action n'est pas encore élucidé. Des auteurs comme Mather et Laughlin $(1976,1977)$ pensent que le stockage retarderait l'éclosion en retardant l'initiation du développement embryonnaire et ou en ralentissant la vitesse de croissance des embryons. Decuypere ef al. (1979) ont observé que le taux sérique de triiodothyronine $\left(T_{3}\right)$ et de thyroxine $\left(T_{4}\right)$ augmentait au cours des derniers jours d'incubation avec un maximum au moment du bêchage indépendamment de la

(1) Correspondance : Prof. Muambi Shambuyi, Faculté des Sciences, B.P. 190 Kinshasa XI/Zaïre. 
température et de la durée d'incubation. Plusieurs observations ont démontré que les hormones thyroïdiennes jouent un rôle dans le développement des embryons de poulet. C'est ainsi que l'injection d'hormones thyroïdiennes accélère l'éclosion tandis que l'injection de goitrogènes la retarde (Freeman et Vince, 1974). Le blocage de la conversion de $T_{4}$ en $T_{3}$ au stade prénatal par l'acide iopanoïque provoque une chute du taux de $T_{3}$ sérique et prolonge la période d'incubation (Decuypere et al., 1980). Un certain niveau d'hormones thyroïdiennes est nécessaire pour que l'éclosion ait lieu normalement.

Comme le stockage des œufs prolonge aussi la durée d'incubation (Bohren et al., 1961 ; Mather ef Laughlin, 1976), nous nous sommes demandé s'il n'y avait pas un rapport entre la durée de stockage des œufs à couver et le taux d'hormones thyroïdiennes dans le sérum des embryons de poulet.

Le but de la présente recherche a donc été de déterminer le taux de $T_{3}$ et $T_{4}$ dans le sang des embryons de poulet à la fin de la période d'incubation en fonction de la durée de conservation des œufs.

\section{Matériel et méthodes.}

Les œufs que nous avons utilisés provenaient des poules Rhode Island Red, du Centre Animalier de la KUL dans leur première année de ponte. Une centaine d'œufs ont été récoltés el pesés tous les 3 jours du 26 avril au 12 mai 1980 pour constituer six groupes d'œufs dont la durée de conservation fut respectivement de $1,5,8,11,14$ et 17 jours.

Les œufs ont été conservés dans des chambres à $12^{\circ} \mathrm{C}$ et 90 à 95 p. 100 d'humidité relative, conditions considérées comme optimales.

Au cours du stockage et de l'incubation, les œufs étaient posés sur la pointe. Ils n'ont éfé retournés qu'au cours de l'incubation et ce automatiquement, chaque heure, d'un angle de $90^{\circ}$. Durant l'incubation, la température a été maintenue à $37,8^{\circ} \mathrm{C} \pm 0,1^{\circ} \mathrm{C}$ et l'humidité relative à $60 \pm 1$ p. 100.

Pour chaque groupe de conservation nous avons prélevé 6 embryons le 19e jour d'incubation, 12 le $20^{\mathrm{e}}$ jour dont 6 avant et 6 après la perforation de la chambre à air et 6 embryons après le bêchage. Des échantillons de sang ont été pris dans les ventricules cardiaques. Le dosage de $T_{3}$ et $T_{4}$ a éfé effectué par la méthode de « radioimmunoassay » (RIA) décrite par Decuypere (1979).

\section{Résultat et discussion.}

La figure 1 représente les taux de $T_{3}$ et $T_{4}$ aux périodes d'incubation où nous avons procédé au prélèvement de sang des embryons. L'analyse de la variance effectuée sur ces taux est reprise dans le tableau 1.

Nous constatons que la durée de conservation des œufs n'influence pas le niveau de $T_{3}, T_{4}$ ou $T_{3} / T_{4}$ sérique. Par contre l'interaction $B \times D$ est significative pour $T_{3}$ et 
TABLEAU 1

Analyse de la variance des taux de $T_{3}$ ef $T_{4}$

\begin{tabular}{|c|c|c|c|c|}
\hline \multirow{2}{*}{ Sources de variation } & \multirow{2}{*}{$\begin{array}{l}\text { Degrés de } \\
\text { liberté }\end{array}$} & \multicolumn{3}{|c|}{ Valeurs de F } \\
\hline & & $T_{3}$ & $\mathrm{~T}_{4}$ & $\mathrm{~T}_{3} / \mathrm{T}_{4}$ \\
\hline $\begin{array}{l}\text { Durée de conservation }(B) \ldots \ldots \ldots \ldots \\
\text { Jours de prélèvement }(D) \ldots \ldots \ldots \ldots \\
\text { Interaction }(B \times D) \ldots \ldots \ldots \ldots \ldots\end{array}$ & $\begin{array}{l}(6-1)=5 \\
(4-1)=3 \\
5 \times 3=15\end{array}$ & $\begin{array}{l}0,56 \\
49,53 * * * \\
2,02 *\end{array}$ & $\begin{array}{l}0,88 \\
20,35 * * * \\
0,74\end{array}$ & $\begin{array}{l}0,75 \\
39,76 * * * \\
2,07 * *\end{array}$ \\
\hline
\end{tabular}

${ }^{* * *} P \leqslant 0,001 ;{ }^{* *} P \leqslant 0,01 ;{ }^{*} P \leqslant 0,05$.

partant pour $T_{3} / T_{4}$. II y aurait donc une variation différentielle de $T_{3}$ vers la fin de l'incubation en fonction de la durée de conservation. En effet, au bêchage, les groupes provenant des œufs qui ont été stockés plus longtemps montrent une tendance à des taux de $T_{3}$ et dès lors à des rapports $T_{3} / T_{4}$ plus bas, allant de pair avec prolongation de la durée d'incubation.

Nous avons constaté une hausse du taux de $T_{3}$ ef $T_{4}$ dans le sérum des embryons de poulet après la perforation de la chambre à air et encore davantage lors du bêchage confirmant ainsi les données de Decuypere et al. (1979).

Le fait que nous avons prélevé le sang au même âge chronologique jusqu'au 20 jour (avant la pénétration de la chambre à air) pourrait expliquer davantage l'interaction constatée entre la durée de conservation et le jour de prélèvement. La tendance à des taux de $T_{3}$ et dès lors à des rapports $T_{3} / T_{4}$ plus bas (allant de pair avec une prolongation de la durée d'incubation) lorsque la durée de conservation augmente (fig. 1), esł à mettre en rapport avec des expériences de Decuypere et al. (1980). Dans ces expériences le blocage de la conversion de $T_{4}$ en $T_{3}$ au stade prénatal par l'acide iopanoïque provoquait également une chute du taux de $\mathrm{T}_{3}$ sérique, $\mathrm{du}$ rapport $T_{3} / T_{4}$ ainsi qu'une prolongation de la durée d'incubation. Ceci prouve que la $T_{3}$ est l'hormone thyroïdienne la plus active dans les processus conduisant à l'éclosion des poussins.

La figure 1 montre que le taux de $\mathrm{T}_{3}$ après le bêchage est d'autant plus élevé que la durée de conservation de l'œuf a éfé plus courte, le taux de $\mathrm{T}_{3}$ du groupe 17 pouvant être considéré comme anormalement élevé. Le stockage des œufs à couver influencerait la durée d'incubation en agissant sur la conversion de $T_{4}$ en $T_{3}$ : le retard à l'éclosion serait dû à une inhibition de la conversion de $T_{4}$ en $T_{3}$. Mais la où les substances inhibitrices qui seraient produites au cours du stockage des œufs sont encore à déterminer.

\section{Conclusion.}

1) Les taux sériques de $T_{3}$ et $T_{4}$ ne sont pas influencés significativement par la durée de conservation de l'œuf mais bien par l'âge des embryons. Nous avons constaté une interaction significative entre les deux facteurs. 


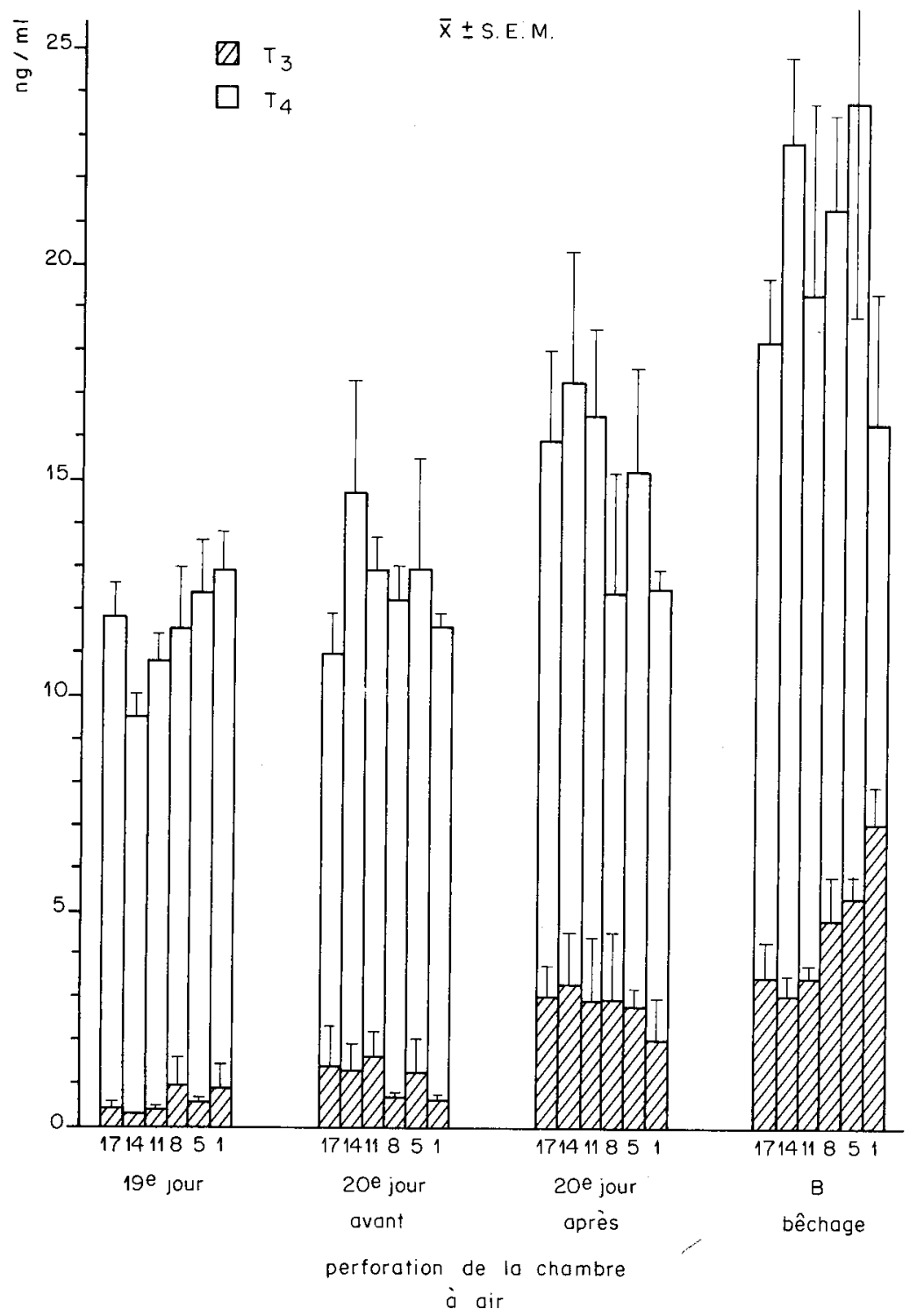

FIG. 1. - Variation du taux sanguin de $\mathrm{T}_{3}$ et $\mathrm{T}_{4}$ (en $\mathrm{ng} / \mathrm{ml}$ ), au cours des $19^{\mathrm{e}}$ ef $20^{\mathrm{e}}$ jours d'incubalion (avant et après perforation de la chambre à air) et lors du bêchage, en fonction de la durée de conservation des œufs (de 1 à 17 jours).

2) Le passage à la respiration pulmonaire au moment du bêchage, avant l'éclosion, provoque une élévation du taux de $T_{3}$ dans le sang, preuve que la $T_{3}$ est l'hormone thyroïdienne la plus active dans les processus conduisant à l'éclosion des poussins. 


\section{Références}

BOHREN B. B., CRITTENDEN L. B., KING R. T., 1961. Hatching time and hatchability in the fowl. Poult. Sci., 40, 620-633.

DECUYPERE E., 1979. Onderzoek naar differentiele effecten van broed-temperatuurschema's op morfogenetische, fysiologische en voortplantingscriteria bij proefdieren van een R.I.R. pluimveepopulatie. Agricultura, 27, 66-280.

DECUYPERE E., NOUWEN E. J., KUHN R. R., GEERS R., MICHELS H., 1979. lodohormones in the serum of chicks embryos and posthatching chickens as influenced by incubation temperature relationship with the hatching process and thermogenesis. Ann. Biol. anim. Bioch. Biophys., 19, 1713-1723.

DECUYPERE E., MICHELS H., KUHEN E. R., 1980. Thyroid hormones before and during the hatching process in chickens. Effects of low temperature and iopanioc acid treatment. Ann. Endocrin. (Abstr.) (in press).

FREEMAN B. M., VINCE A. M., 1974. Development of the avian embryo. Chapman and Hall, London. MATHER C. M., LAUGHLIN K. P., 1976. Storage of hatching eggs; the effect on total incubation period. Brit. Poult. Sci., 17, 471-479.

MATHER C. M., LAUGHLIN K. P., 1977. Storage of hatching eggs : the effects on early embryonic development. Brit. Poult. Sci., 18, 597-603. 